\title{
Overcoming Challenges to Effective Application of IT Research Results: A Framework for Encapsulating the Context and Findings of Research Studies
}

\author{
Degan Kettles \\ Univ. of Central Oklahoma \\ DKettles@uco.edu
}

\author{
Uday Kulkarni \\ Arizona State Univ. \\ Uday.Kulkarni@asu.edu
}

\author{
Daniel Mazzola \\ Arizona State Univ. \\ Dan.Mazzola@asu.edu
}

\author{
Robert St. Louis \\ Arizona State Univ. \\ St.Louis@asu.edu
}

\begin{abstract}
Research studies frequently yield conflicting results. Resolving these conflicts is a grand challenge to effective application of research results. This paper presents a new framework for encapsulating the context and findings of research studies into a dimensional knowledge base which makes it easy to identify the conflicting results, and to explore the differences in context that might explain the conflicting findings. The framework is illustrated using the knowledge sharing domain. The Information Systems literature identifies over 100 variables associated with knowledge sharing, and the findings across different studies have frequently been contradictory. This paper shows how to capture the relevant contextual information, store the information in a dimensional document mart, and use the information to detect and reconcile seemingly inconsistent findings.
\end{abstract}

\section{Introduction}

Research studies frequently yield conflicting results. One of the key responsibilities of researchers is to investigate, understand, and reconcile these conflicting interpretations. The context in which the studies were conducted provides important clues for explaining why the results are contradictory. We argue that one cannot perform a critical analysis of any research study area without considering certain foundational elements. We illustrate our unique framework for encapsulating the context and findings of research studies by using a collection of research studies in a specific domain - knowledge management and knowledge management systems. We selected this problem domain because it has many unresolved questions, it is a popular research domain for both academics and practitioners, and it is rife with variations in problem settings, theoretical bases, dependent and independent variables included (and excluded), and conflicting conclusions; making it a challenging and interesting domain to use as an illustrative example in our research.

The purpose of our study is to present a structured methodology to unearth the causes of conflicting results in a given research domain. As an example, there were ten research studies published during a span of 5 years in leading Information Systems (IS) journals that evaluated the impact of extrinsic rewards on knowledge sharing. Of these, five found a positive relationship, four found a negative relationship, and one found no relationship (Bock et al. [1], Bordia et al. [2], Han and Anantatmula [7], Jian and Jeffries [9], Kankanhalli et al. [10], Siemsen et al. [16], Lin [13], Quigley et al. [15], He and Wei [8]). Researchers and practitioners interested in this phenomenon need to examine the foundational elements underlying these research studies in order to appropriately interpret the conclusions. Furthermore, researchers wanting to pursue this line of research need to understand the nuances introduced by the differences between the foundational elements.

Against the above backdrop, the goals of this research are to: (1) identify the foundational elements of quantitative research studies, (2) present the structure of a novel knowledge base for capturing and retrieving relevant information about those foundational elements; and (3) explain how to use the knowledge base to facilitate easy exploration of the causes of conflicting results of research studies.

In the following sections we first explain the foundational elements needed for understanding research findings and the conflicts among them. We then explain why we selected knowledge management systems as our problem domain, illustrate the extent to which conflicting results exist among the research studies in this problem domain, illustrate how to encapsulate the relevant information about those foundational elements into a dimensional knowledge base, show how to use that knowledge base to identify and reconcile conflicting study results, and discuss the 
implications of our study for both academics and practitioners.

\section{Foundational Elements}

Mathiassen, Chiasson, and Germonprez [14] develop the notion of style composition to understand how authors structure their premises and inferences for presenting their contributions in action research. Through a review of the literature, they identify a set of foundational elements for evaluating action research (research that solves practical problems while also contributing to theory). These elements can be categorized as: area of concern, problem setting, conceptual framework, methods of investigation, and contribution. Our purpose is to enable both researchers and practitioners to more easily identify and resolve inconsistencies and conflicts among the findings of quantitative research studies, and to evaluate and apply these contributions in practice. To accomplish this purpose, we develop a framework and a process for encapsulating the context and findings of quantitative research studies. We use Mathiassen et al.'s work as a partial foundation to begin the categorization of the needed information. To complete the foundation, we examined the literature on statistical design for research. Kish [12] discusses the representation, randomization, and realism of quantitative research studies. He identifies five classes of variables that should be considered whenever a statistical inference is made: predictand (dependent) variables, predictor variables, control variables, disturbing variables, and randomized variables. Most research studies either do not discuss disturbing variables, or argue that there are none. Likewise, most research studies do not elaborate on the randomized variables. However almost every research study identifies the predictand variables, the predictor variables, and the control variables, and describes how they were operationalized. Because only these three classes of variables are universally present, we limit our attention to just these three.

Using Mathiassen et al.'s foundational elements of action research and Kish's classification of research variables, we developed a set of evaluative elements for findings of quantitative research studies. The elements, and our reason for including each of the identified elements, are shown in Table 1. The information listed in Table 1 is necessary to evaluate study findings, and to resolve inconsistencies among studies. Unfortunately, it is difficult to dig this information out of articles. Moreover, when reading an article, it is not clear whether other articles have examined the same predictand and whether other articles have produced conflicting results. In the following section we illustrate in detail the challenges involved with evaluating findings from a literature review conducted in a popular research area. We then resolve these evaluation challenges by building on the evaluation elements identified in Table 1 and creating a generic framework useful to both researchers and practitioners.

\section{Table 1: Evaluative Elements for Findings of Quantitative Research Studies}

\begin{tabular}{|c|c|}
\hline $\begin{array}{c}\text { Evaluative } \\
\text { Element }\end{array}$ & $\begin{array}{l}\text { Reason for } \\
\text { Inclusion }\end{array}$ \\
\hline $\begin{array}{l}\text { Predictand } \\
\text { Variable }\end{array}$ & $\begin{array}{l}\text { The predictand (dependent) variable is the } \\
\text { variable that researchers and practitioners want } \\
\text { to understand or influence. }\end{array}$ \\
\hline $\begin{array}{l}\text { Predictor/ } \\
\text { Control } \\
\text { Variables }\end{array}$ & $\begin{array}{l}\text { The aim of a research study is to find and } \\
\text { measure the relationship between the predictor } \\
\text { variables and the predictand variable. } \\
\text { Researchers often want to understand the } \\
\text { relationship; practitioners want to use the } \\
\text { relationship. Control variables, although not the } \\
\text { focus of the study, often are required to either } \\
\text { reduce randomness or eliminate bias. A failure } \\
\text { to include control variables often is the reason } \\
\text { for non-significant and inconsistent results. }\end{array}$ \\
\hline $\begin{array}{l}\text { Statistical } \\
\text { Significance }\end{array}$ & $\begin{array}{l}\text { If the results are not statistically significant, } \\
\text { researchers cannot say there was any effect, and } \\
\text { practitioners cannot have any confidence that an } \\
\text { action will have the intended effect. }\end{array}$ \\
\hline Theory & $\begin{array}{l}\text { An understanding of causality can come only } \\
\text { from theory. Researchers must understand the } \\
\text { theory in order to understand the causal factors } \\
\text { at work. Practitioners must understand the } \\
\text { theory in order to have any confidence in the } \\
\text { results. Without theory, there is no } \\
\text { generalizability and no basis for practitioners to } \\
\text { take action. }\end{array}$ \\
\hline $\begin{array}{l}\text { Consistency } \\
\text { of Results }\end{array}$ & $\begin{array}{l}\text { If the study results are not consistent with } \\
\text { theory, then researchers must do further work to } \\
\text { resolve the inconsistency, and practitioners } \\
\text { should be very cautious about acting on the } \\
\text { results. }\end{array}$ \\
\hline $\begin{array}{l}\text { Research } \\
\text { Method }\end{array}$ & $\begin{array}{l}\text { Differences in the research methods could } \\
\text { explain differences in the study results. Also, an } \\
\text { inappropriate research method could invalidate } \\
\text { the study results. }\end{array}$ \\
\hline Subject Type & $\begin{array}{l}\text { Differences in subject type could explain } \\
\text { differences in study results. Moreover, certain } \\
\text { subject types may be inappropriate for some } \\
\text { research studies. }\end{array}$ \\
\hline Citation & $\begin{array}{l}\text { Both researchers and practitioners need to be } \\
\text { able to locate the source study. }\end{array}$ \\
\hline
\end{tabular}

\section{The Knowledge Management Domain}

Knowledge management is a popular topic with literally hundreds of papers written about it in leadings IS journals. One explanation for the intense interest in the area is that knowledge is considered the key to 
competitive advantage and superior corporate performance (Grant [6]). This makes research on knowledge management and knowledge management systems important to any organization that wishes to make more effective use of its current resources and create new opportunities through creative uses of knowledge.

Despite numerous efforts made by academics and practitioners to understand and create successful knowledge management systems, much remains to be done. When discussing knowledge management systems, Bush and Tiwana [3] poignantly state: "Unfortunately, however, successful knowledge networks represent the occasional island dotting a sea of failures. While many organizations are eager adopters of knowledge network systems, individual users frequently abandon them, leaving a trail of million-dollar paperweights." Therefore, despite the many findings that have been made regarding the causes and inhibitors of knowledge sharing, getting workers to share knowledge in an organizational setting has proven difficult.

One way to start to solve the long-standing challenge of getting people to share knowledge, particularly in knowledge management systems, is to critically analyze the existing knowledge base found in leading journals. Therefore, we begin our inquiry by conducting a systematic review of the Knowledge Management (KM) literature. In knowledge management studies, the typical outcome variable is either the consumption of knowledge or the contribution of knowledge, although some studies discuss both simultaneously. The domain of our literature review was limited to the causes of knowledge sharing, because it is a critical precursor to the consumption of knowledge, and because a significant body of research addresses this outcome variable specifically. The literature review began with the top 12 IS journals formerly listed on the Association for Information Systems' website, www.aisnet.org. In each of these journals, we searched for the following keywords in titles, abstracts, text, and keyword lists: knowledge, community, communities, network, forum, social, team, and group.

The time frame of the articles was the complete set of available digital content for each journal up through early 2014, which ranged from 10 to 21 years. Over 2,000 articles matched these criteria, and their abstracts and bodies were skimmed to identify articles that explored the causes of knowledge sharing with and without the use of an information system. Approximately 250 articles were marked as likely candidates to contain empirical findings related to knowledge sharing, and were examined more closely. Some of these articles focused on topics unrelated to knowledge sharing, such as how knowledge impacts productivity or how to determine the optimum investment in knowledge workers, and were excluded from this study. Qualitative studies, such as case studies that mainly consisted of narratives or untested propositions, also were excluded from the present study.

The remaining articles contained quantitative results related to knowledge sharing, and their references were examined to locate additional studies for inclusion in this review. The end result of this process yielded a total of 45 empirical articles that highlight the factors associated with knowledge sharing.

The 45 articles related to knowledge sharing were closely examined, and a list was made of the factors that were hypothesized to impact knowledge sharing. It is noteworthy that over unique 100 factors have been examined for their impact on knowledge sharing. Researchers and practitioners attempting to understand the causes of knowledge sharing are faced with a daunting quantity of not only explanatory factors, but also findings related to those factors. Of even greater concern, however, is our observation that findings related to individual factors were seldom verified by other studies, and in the few cases where attempts at verification were attempted, the results often were inconsistent.

A summary of the findings related to factors that were tested in more than one study is contained in Table 2. Only 34 factors were tested more than once, and among those only 13 were both significant (in most cases at the 5\% level) and consistent across studies. For the other 21 factors, 2 were non-significant across studies, and 19 were inconsistent across studies. One would expect to see more consistency among the results of studies that are designed carefully and have factors that were chosen for strong theoretical reasons.

Any literature review that uncovers large numbers of findings, and particularly mixed findings, presents challenges for both researchers and practitioners. Researchers need to understand the causal mechanisms underlying previous findings in order to build off of that knowledge in future research. However, keeping track of all the relevant contextual dimensions that characterize a given set of studies and results is difficult when several studies are involved. Practitioners who want to use research results to improve their decision-making will be similarly challenged to understand the contextual differences involved in the results of studies. Because the generalizability of research results is dependent on the context, and the context can vary greatly from study to study, consumers of research studies would be greatly aided by a method for comparing study findings based 
on context. In the following section we build on the evaluative elements we introduced earlier and present a framework for encapsulating the context and findings of research studies.

Table 2: Results for Explanatory Factors

\begin{tabular}{|c|c|c|}
\hline Factor & Findings & $\begin{array}{l}\text { Conflicting } \\
\text { Results? }\end{array}$ \\
\hline Anonymity & ++ & No \\
\hline Attitude & $+\mathrm{N}$ & Yes \\
\hline $\begin{array}{l}\text { Attitude toward knowledge } \\
\text { sharing }\end{array}$ & +++ & No \\
\hline Codification Difficulty & $\mathrm{N}-$ & Yes \\
\hline $\begin{array}{l}\text { Community-related outcome } \\
\text { expectations }\end{array}$ & $\mathrm{N}+$ & Yes \\
\hline Enjoyment in Helping Others & $+++\mathrm{N}$ & Yes \\
\hline Evaluation Apprehension & -- & No \\
\hline $\begin{array}{l}\text { Evaluation Apprehension * } \\
\text { Extrinsic Reward }\end{array}$ & $+\mathrm{N}$ & Yes \\
\hline Extrinsic Reward & $+++++-\mathrm{NNNN}$ & Yes \\
\hline Training & ++ & No \\
\hline Gender & $++\mathrm{NN}$ & Yes \\
\hline Group Dispersion & -- & No \\
\hline Group Identification & $\mathrm{NN}$ & No \\
\hline Group Size & -- & No \\
\hline Intention to Share Knowledge & ++ & No \\
\hline Intrinsic Motivation & ++ & No \\
\hline Knowledge Self-efficacy & +++ & No \\
\hline Managerial Influence & $++++\mathrm{NN}$ & Yes \\
\hline Offline Activity & $+\mathrm{N}$ & Yes \\
\hline Organizational Identification & $+\mathrm{N}$ & Yes \\
\hline Perceived Ease of Use & $\mathrm{NNN}$ & No \\
\hline Perceived Expertise & $+\mathrm{N}$ & Yes \\
\hline Perceived Usefulness & +++ & No \\
\hline Personal Outcome Expectations & $++\mathrm{NN}$ & Yes \\
\hline Pro-sharing Norms & $++\mathrm{N}$ & Yes \\
\hline Reciprocity & $+-\mathrm{NNN}$ & Yes \\
\hline Shared Understanding & +- & Yes \\
\hline Social Interaction Ties & +++ & No \\
\hline Social Isolates & ++ & No \\
\hline Tenure in organization & $+++\mathrm{N}$ & Yes \\
\hline Tenure in online community & $+\mathrm{N}$ & Yes \\
\hline Trust & $++\mathrm{NN}$ & Yes \\
\hline Usefulness & $+\mathrm{N}$ & Yes \\
\hline User Commitment & $+\mathrm{N}$ & Yes \\
\hline User Motivation & ++ & No \\
\hline \multicolumn{3}{|c|}{$\begin{array}{l}\text { Note: Each finding related to knowledge contributions is } \\
\text { marked as positively associated }(+) \text {, negatively associated (-), } \\
\text { or not significant }(\mathrm{N}) \text { at the requisite level in the study, } \\
\text { normally 5\%. Multiple entries indicate multiple studies. }\end{array}$} \\
\hline
\end{tabular}

\section{Framework for Encapsulation}

The star schema has been widely adopted to encapsulate context and share data to support decisionmaking. We propose using it as part of a framework for enabling researchers and practitioners to evaluate the contributions of articles and resolve conflicting findings among articles. A star schema is based on a relational data model but with important restrictions [11]. Every star schema includes one table at its center called a fact table. Each record in the fact table typically contains one or more numerical measures or facts. The fact table is surrounded by a set of smaller tables called dimension tables, which provide context for the facts. This relatively simple schema format facilitates rapid slicing and dicing of facts based on context.

Star schemas have not been widely used for document management, but their use has been suggested $[4,5]$. In a document management context, the dimensions are useful ways to group or filter documents. If a dimension table were to be created for each of the evaluative elements in Table 1 , then we would be able to group documents by predictand variable, predictor/control variable, theory, etc., and any combination thereof. This would be very useful to both researchers and practitioners. For example, a researcher could quickly find all of the studies that examined knowledge sharing through online repositories, see what variables were used as predictors, and determine whether there were any conflicting results. Moreover, if there were conflicting results, the researcher could quickly see if they might be explained by differences in subject type, research method, or control variables.

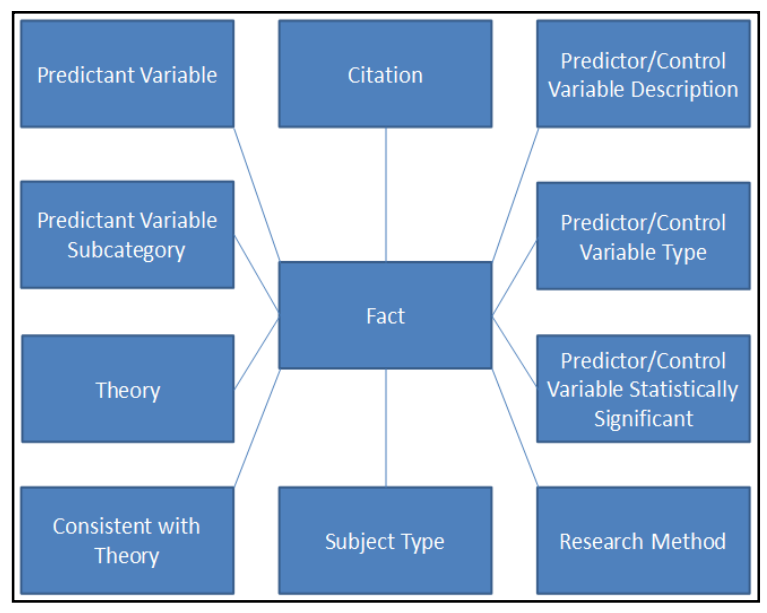

Figure 1. Framework for Encapsulating Evaluative Elements

Figure 1 shows how a given study's findings (the facts) and context can be captured. The Predictand Variable Subcategory dimension was added because it provides a useful level of contextual granularity that wasn't initially recognized. After creating the initial diagram, we created corresponding database tables in a 
SQL database for each of the tables in the star schema, and entered the findings of the 45 articles from our literature review in those database tables.

Each article that is added to the document warehouse must result in the addition of one or more rows to the fact table. However, adding new articles to the document warehouse will not necessarily result in the addition of new rows to the dimension tables. For example, the number of rows in the Predictor/Control Variable Statistically Significant dimension table will never have more than three rows in it. The only choices are Negative and Significant, Not Significant, and Positive and Significant. The number of rows in the other dimension tables generally will increase as documents are added to the document mart, but will not necessarily increase each time that a document is added. All of the theories referenced in an added article, for instance, may have been referenced by articles that already are in the document warehouse. The Access Database containing the tables for the complete set of 45 articles is available to anyone upon request. Table 3 provides detailed specifications for the information that is in the fact and dimension tables.

\section{Table 3: Construction of the Fact and Dimension Tables}

\begin{tabular}{|l|l|}
\hline Citation & $\begin{array}{l}\text { This table contains the APA citation } \\
\text { information for one article that is in the } \\
\text { warehouse. There are as many rows in this } \\
\text { table as there are documents in the document } \\
\text { warehouse. }\end{array}$ \\
\hline $\begin{array}{l}\text { Categorized } \\
\text { Predictand } \\
\text { Variable }\end{array}$ & $\begin{array}{l}\text { This table contains the description for a broad } \\
\text { categorization of the predictand variables } \\
\text { used in knowledge sharing studies. Four } \\
\text { major categories of predictand variables were } \\
\text { used: intention to share knowledge, actual } \\
\text { knowledge sharing, intention to hoard } \\
\text { knowledge, actual knowledge hoarding. }\end{array}$ \\
\hline $\begin{array}{l}\text { Operationalized } \\
\text { Predictand } \\
\text { Variable }\end{array}$ & $\begin{array}{l}\text { This table represents the operationalization of } \\
\text { a predictand variable in one or more } \\
\text { documents stored in the warehouse. A } \\
\text { predictand variable can be operationalized } \\
\text { the same way in multiple documents. When } \\
\text { coding a research finding into the fact table, } \\
\text { predictand variables with different names but } \\
\text { equivalent definitions were standardized to } \\
\text { use the same name. }\end{array}$ \\
\hline $\begin{array}{l}\text { Operationalized } \\
\text { Predictor/ } \\
\text { Control }\end{array}$ & $\begin{array}{l}\text { This table represents the operationalization of } \\
\text { a predictor/control variable in one or more } \\
\text { Variables }\end{array}$ \\
$\begin{array}{l}\text { documents contained in the warehouse. A } \\
\text { predictor/control variable can be } \\
\text { operationalized the same way in multiple } \\
\text { documents. When coding a research finding } \\
\text { into the fact table, predictor/control variables } \\
\text { with different names but equivalent } \\
\text { definitions were standardized to use the same } \\
\text { name. }\end{array}$ \\
\hline
\end{tabular}

\begin{tabular}{|c|c|}
\hline $\begin{array}{l}\text { Predictor/ } \\
\text { Control } \\
\text { Variable Type }\end{array}$ & $\begin{array}{l}\text { Predictor/Control variables can be } \\
\text { categorized as human, organizational, and } \\
\text { platform. The interactions of these variable } \\
\text { types can be classified as human- } \\
\text { organizational, human-platform, and } \\
\text { organizational-platform. This table contains } \\
\text { those } 6 \text { classifications. }\end{array}$ \\
\hline \begin{tabular}{|l|} 
Predictor/ \\
Control \\
Variable \\
Statistically \\
Significant
\end{tabular} & $\begin{array}{l}\text { Each tested relationship between a } \\
\text { predictor/control variable and its predictand } \\
\text { can be classified as either negative and } \\
\text { significant, not significant, or positive and } \\
\text { significant. This table contains those three } \\
\text { classifications }\end{array}$ \\
\hline Theory & $\begin{array}{l}\text { Each tested relationship between a } \\
\text { predictor/control variable and its predictand } \\
\text { should be supported by some theory. This } \\
\text { table lists all of the theories that were used to } \\
\text { support tested relationships in any article that } \\
\text { is in the document warehouse. A row labeled } \\
\text { "no theory" is included to allow for the } \\
\text { possibility that some tested relationships may } \\
\text { not be supported by theory. }\end{array}$ \\
\hline $\begin{array}{l}\text { Consistent with } \\
\text { Theory }\end{array}$ & $\begin{array}{l}\text { Each tested relationship between a } \\
\text { predictor/control variable and its predictand } \\
\text { can be classified as either consistent, not } \\
\text { consistent, or indeterminate with respect to } \\
\text { the theory used to predict the relationship; or } \\
\text { as not having any theory associated with the } \\
\text { relationship. This table contains these } \\
\text { classifications }\end{array}$ \\
\hline $\begin{array}{l}\text { Research } \\
\text { Method }\end{array}$ & $\begin{array}{l}\text { A specific research method must be used to } \\
\text { test each relationship between a } \\
\text { predictor/control variable and its predictand. } \\
\text { This table lists all of the research methods } \\
\text { that were used to test relationships in any } \\
\text { document that is in the document store. }\end{array}$ \\
\hline Subject Type & $\begin{array}{l}\text { Each experiment or survey must have a } \\
\text { subject type. This table lists all of the } \\
\text { different types of subjects that were used in } \\
\text { any study in any document in the document } \\
\text { store. The row labeled no subjects is included } \\
\text { to allow for the possibility that firm rather } \\
\text { than subject data may have been used in } \\
\text { some studies. }\end{array}$ \\
\hline Fact & $\begin{array}{l}\text { The granularity of the fact table is predictor } \\
\text { by predictand by document by research } \\
\text { methodology by subject type by theory. That } \\
\text { is each row in the fact table represents a } \\
\text { tested relationship between a } \\
\text { predictor/control variable and its predictand } \\
\text { that occurred in a specific document, that } \\
\text { used a specific methodology, that used a } \\
\text { specific subject type, and that was supported } \\
\text { by a specific theory. The only additive fact } \\
\text { that occurs in this table is the number } 1 \text {, to } \\
\text { support counting the number of times that a } \\
\text { particular relationship was tested in a specific } \\
\text { context. }\end{array}$ \\
\hline
\end{tabular}

Two of the dimension tables described in Table 3 require additional clarification. In the Categorized 
Predictand Variable Dimension, the broad categories for the predictand variable were constructed to provide a useful grouping for persons that want to explore the findings of research studies related to knowledge sharing. The literature on knowledge sharing includes studies that have looked at both intention to share and actual sharing of knowledge, as well as intention to hoard and actual hoarding of knowledge. This dimension table could be eliminated, but users would lose the ability to group articles based on this classification. We believe categorizing the predictand variable will help both researchers and practitioners

Similarly, in the Predictor/Control Variable Type Dimension, the entries did not come directly from the literature review but were the result of an analysis of variables specific to this domain. The variable types that we identified are human, organizational, and platform. Organizational factors represent influences in the workplace that affect levels of knowledge sharing, including financial incentives, behavioral norms, and job roles. Platform factors represent both the technology features of the knowledge sharing platform and the virtual community contextual features such as group size and member proximity. Lastly, human factors encompass individual traits as well as social relations among people, and include items such as intrinsic motivation and shared language. Each of these factors can be a major driver or inhibitor of knowledge sharing.

\section{Example}

Implementing the framework shown in Figure 1 begins with coding the findings in each research article. We use the Bordia et al. study to demonstrate the processes of coding an article [2]. The Bordia study involves six findings related to knowledge sharing, and each of these findings is coded in the Fact table shown in Appendix A. The first finding in the article can be summarized as: Social Exchange Theory suggests that evaluation apprehension will reduce an individual's willingness to share information; in a survey of workers, the human factor, evaluation apprehension, was found to have a statistically significant negative impact on intension to share knowledge when communicating interpersonally, which is consistent with Social Exchange Theory. The first row of the Fact table contains the entries that summarize this finding. It should be noted that each field in the Fact table, other than FactID and Count, is a foreign key from a dimension table. For ease of exposition, we use text keys rather than numeric keys for all of the dimensions other than citation.

Note that Row 1 of the fact table summarizes finding one from the Bordia et al. article. That is, from
Row 1, it is clear that: 1) Social Exchange Theory suggests that evaluation apprehension will affect an individual's willingness to share information; and 2) in a survey of workers, the human factor, evaluation apprehension, was found to have a statistically significant negative impact on intension to share knowledge when communicating interpersonally, which is consistent with Social Exchange Theory.

When coding across many articles it is important not to enter variables with identical definitions but different names. Instead, common names for equivalent variables should be used. For the first two findings in the Bordia article the variable name Evaluation Apprehension was used. For the third and fourth findings the variable name from the study, Perceived Benefit, was replaced with the standardized term Extrinsic Reward that was used in many other studies.

The PredictorVarTypeName column is a key to the Predictor_Variable_Type table and is a category we introduced during the coding process to differentiate between the types of independent variables used in the studies: some of which captured interpersonal influences, some of which captured organizational influences, and some of which captured platformspecific influences. This facilitates a comparison of the types of influences that different studies controlled for. The last entry in the Fact table for each finding is the Count field and it always holds the value of 1--which is useful when the data is later analyzed in a pivot table. The rest of the entries are straight forward enough to not require further explanation.

After an article is properly coded, its fact table can be analyzed using a pivot table, a tool that exists natively in Microsoft Access, Microsoft Excel, and many other software products. A pivot table facilitates slicing and dicing data to uncover important information, and one way this capability can be applied to a literature review is to analyze mixed findings. One variable from the knowledge sharing literature that exhibits mixed findings across many studies is Extrinsic Reward.

The following set of figures correspond to investigating the findings related to the variable Extrinsic Reward in the Bordia article, where it exhibits mixed results within the same study. Figure 2 shows the result of dragging the Count field from the Field List box in the upper right to the Values box in the lower right, and the CatPredictandVar field from the Field List box to the Row Labels Box in the lower right region of the page. A pivot table is generated on the left hand side of the page and it tells us that 6 findings are present in the fact table that we are using as our data source, and that the dependent variable in each case is Knowledge Sharing. 


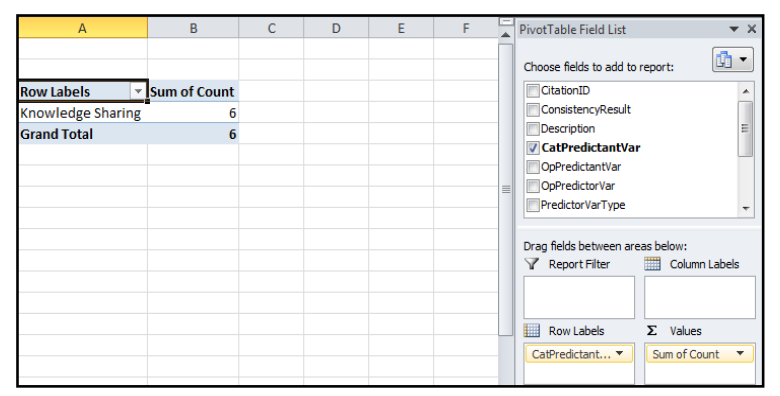

Figure 2.

The next question that we might ask is which variables have been investigated for their impact on knowledge sharing in our fact table. To do this the field OpPredictorVar would be pulled down from the Field List and placed beneath the field CatPredictandVar in the Row Labels section in the lower right. The resulting change in the pivot table is shown in Figure 3. The pivot table now shows the three different variables that were explored in relation to the dependent variable knowledge sharing, and it shows under the Sum of Count column that each variable has been associated with two findings. If the fact table included a larger literature review, then some variables would have large numbers of findings associated with them while others might have just one.

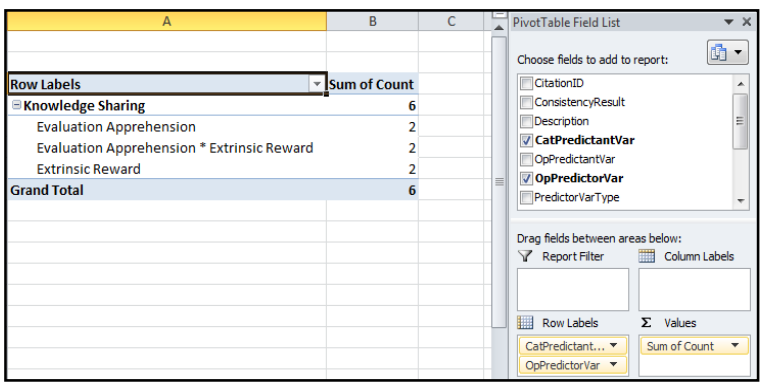

Figure 3.

The next question we might ask is whether the findings related to these variables resulted in outcomes that were consistent with theory. To do this we drag the ConsistencyResult field to the bottom of the Row Labels list and the resulting pivot table is shown in Figure 4. This shows us that while the first variable exhibited results consistent with hypotheses each time it was tested, the same is not true of the other variables tested. In the case of Extrinsic Reward, one finding was consistent with a hypothesis and another was not.

\begin{tabular}{|lr|}
\hline Row Labels & Sum of Count \\
\hline$\Xi$ Knowledge Sharing & 6 \\
\hline$\boxminus$ Evaluation Apprehension & 2 \\
Consistent & 2 \\
$\boxminus$ Evaluation Apprehension * Extrinsic Reward & 2 \\
Consistent & 1 \\
Indeterminate & 1 \\
$\boxminus$ Extrinsic Reward & 2 \\
Consistent & 1 \\
Indeterminate & 1 \\
Grand Total & 6 \\
\hline
\end{tabular}

Figure 4.

Now that a disconcerting problem in the literature has been discovered, the next step is to use the remaining fields to identify potential differences between the circumstances surrounding the consistent and indeterminate finding. One-way to do this would be to add OpPredictandVar to the bottom of the list, as shown in Figure 5. Adding in the dependent variable subcategory shows us that the consistent result came about when knowledge sharing was measured as an intention to share in a knowledge repository, but indeterminate when measured as an intention to share knowledge interpersonally (directly). This result should suggest to a researcher that further research may be needed to see if extrinsic rewards operate differently than expected when using direct communication rather than sharing through a knowledge repository.

The preceding example ended with a comparison of findings based on the dependent variable, but other comparisons could also have been made. For example, it is possible that the research method, subject type, or year could be the only discernible difference between inconsistent findings. These differences are not present in this example because only a single study is being used, but they do occur when multiple studies are being compared.

\begin{tabular}{|lr|}
\hline Extrinsic Reward & 2 \\
$\boxminus$ Consistent & 1 \\
RepositoryKSInt & 1 \\
$\Xi$ Indeterminate & 1 \\
InterpersonalKSInt & 1 \\
\hline
\end{tabular}

Figure 5.

In Figure 6 we present the outcome of comparing three articles that each contained findings related to the variable Extrinsic Reward. The articles used in this comparison are Bordia et al. [2], Kankanhalli et al. [10], and Bock et al. [1]. Among the three studies the variable was examined a total of four times. The order 
of the fields entered into this pivot table is slightly different in this example. Consistency is the first field entered in, followed by the variable significance, dependent variable subcategory, research subject type, and research method. The resulting pivot table shows that findings consistent with theory were observed twice, while in other cases the result was either indeterminate or not consistent (meaning it was found to be directly opposite of the predicted result).

When comparing the three different results for this variable, it stands out that consistent results were found for knowledge sharing through a repository, but not for knowledge sharing in other contexts. The two consistent results came about when the measure was either intention to share knowledge (RepositoryKSInt) or actual shared knowledge (RepositoryKSAct) using a knowledge repository. This indicates that the associated theory is supported by multiple findings in this context. The indeterminate finding took place in a direct communication context, and the not-consistent finding took place in a context when it wasn't specified whether the context included direct communication or repository-based sharing. These problematic results provide evidence that further theory development may be needed in the direct communication contexts.

\begin{tabular}{|cc|}
$\boxminus$ Extrinsic Reward & 4 \\
$\boxminus$ Consistent & 2 \\
$\boxminus$ Positive Significant & 2 \\
$\boxminus$ RepositoryKSAct & 1 \\
$\boxminus$ Workers & 1 \\
Survey & 1 \\
$\boxminus$ RepositoryKSInt & 1 \\
$\boxminus$ Workers & 1 \\
Survey & 1 \\
$\boxminus$ Indeterminate & 1 \\
$\boxminus$ Not Significant & 1 \\
$\boxminus$ InterpersonalKSInt & 1 \\
$\boxminus$ Workers & 1 \\
Survey & 1 \\
$\boxminus$ Not-Consistent & 1 \\
$\boxminus$ Negative Significant & 1 \\
$\boxminus$ GeneralKSInt & 1 \\
$\boxminus$ Workers & 1 \\
Survey & 1 \\
\hline
\end{tabular}

Figure 6.

The additional fields shown in Figure 6 that have not been mentioned so far are also instructive, because they clarify the circumstances under which different findings occurred. In this example the subject types and research methodologies were equivalent among the studies and can be ruled out as the source of different findings. These equivalent contexts may also call attention to the fact that alternatives have not yet been tested and they could be incorporated into future studies, particularly those related to the problematic areas. For example, a researcher might investigate what the result of an incentive would be if actual knowledge sharing were measured rather than intention to share knowledge as reported in a survey.

These examples help clarify the importance of using an approach like the one we have presented. In all but the simplest of literature reviews, it would be difficult to understand all of the different contextual facts related to research findings.

\section{Conclusion}

In this paper we have demonstrated that conducting a literature review can be a daunting task. In the domain of knowledge sharing we have shown that the quantity of articles studied along with many mixed findings make it difficult to adequately grasp what it is we actually know and don't know. One thing that confounds attempts to understand a subject domain such as knowledge management, even after a comprehensive review of its articles, is how to account for the contexts that contributed to different findings. By defining and encapsulating the set of foundational elements which are necessary to understand the context and practical importance of research findings, our novel framework and method of analysis make it possible to easily compare findings and make use of contextual differences to explain possible conflicts or contractions among them. This provides great value to both reviewers and consumers of Information Systems articles.

The new framework we have introduced for conducting literature reviews should be of great value to researchers in fields outside of Information Systems as well. It is appropriate that our field, which specializes in data analysis and decision making techniques, should be the source of innovations that help all fields of research to organize and analyze the bodies of literature that are their key intellectual assets. Each of the dimensions we introduced as part of our framework can be applied to literature reviews to clarify what we know based on existing literature and to spawn future streams in areas that need attention. Although a comprehensive demonstration of how to apply the framework is not feasible in this article, other applications of the dimensions contained in the framework are listed in Appendix B.

As a final note we should mention how this framework can be of benefit to practitioners. Although it is unlikely that practitioners will conduct their own comprehensive literature reviews, they could benefit greatly by working with the fact tables that researchers produce. Business professionals already do a significant amount of data analysis and are familiar 
with using pivot tables. Imagine if instead of reading the literature review section of a recent article on knowledge management to understand what we already know about the causes and impediments of knowledge sharing, they could use a pivot table to quickly comb through over 100 things that have been tested for their impact on knowledge sharing. They could see what helps, what hurts, and under what conditions you get different outcomes. Used in this way, a pivot table of relevant data is likely to lead practitioners to engage more effectively with the specific academic articles that address problems with which they are dealing.

\section{References}

[1] Bock, G., R.W. Zmud, Y. Kim, and J. Lee (2005) "Behavioral Intention Formation in Knowledge Sharing: Examining the Roles of Extrinsic Motivators, SocialPsychological Forces, and Organizational Climate", MIS Quarterly (29)1, pp. 87-111.

[2] Bordia, P., B.E. Irmer, and D. Abusah (2006) "Differences in Sharing Knowledge Interpersonally and Via Databases: The Role of Evaluation Apprehension and Perceived Benefits", European Journal of Work and Organizational Psychology (15)3, pp. 262-280.

[3] Bush, A., and A. Tiwana (2005). "Designing Sticky Knowledge Networks", Communications of the ACM (48)5. pp. 67-71

[4] Corral, K., Schuff, D., Schymik, G, and R. St. Louis (2007) "Architecting a Dimensional Document Warehouse", Business Intelligence Journal (12)2, pp. 34-41.

[5] Corral, K., Schuff, D., Schymik, G, and R. St. Louis (2010) "Strategies for Document Management", International Journal of Business Intelligence Research (1)1, pp. 64-83.

[6] Grant, R.M. 1996. Prospering in Dynamicallycompetitive Environments: Organizational Capability as
Knowledge Integration. Organization Science 7(4) 375387.

[7] Han, B.M., and V.S. Anantatmula (2007) "Knowledge Sharing in Large IT Organizations: A Case Study", Vine (37)4, pp. 421-439.

[8] He, W., and K. Wei (2009) "What Drives Continued Knowledge Sharing? An Investigation of KnowledgeContribution and -seeking Beliefs", Decision Support Systems (46), pp. 826-838.

[9] Jian, G. and L.W. Jeffres (2006) "Understanding Employees' Willingness to Contribute to Shared Electronic Databases", Communication Research (33)4, pp. 242-261.

[10] Kankanhalli, A., B. Tan, and K. Wei (2005) "Contributing Knowledge to Electronic Knowledge Repositories: An Empirical Investigation”, MIS Quarterly (29)1, pp. 113-143.

[11] Kimball, R. (1997). "A dimensional modeling manifesto", DBMS (10)9, pp. 58-70.

[12] Kish, Leslie (1987) Statistical Design for Research. New York: John Wiley \& Sons

[13] Lin, H. (2007) "Effects of Extrinsic and Intrinsic Motivation on Employee Knowledge Sharing Intentions", Journal of Information Science (33)2, pp. 135-149.

[14] Mathiassen, L., M. Chiasson, and M. Germonprez (2012) "Style Composition in Action Research Publication”, MIS Quarterly, (36)2, pp. 347-363.

[15] Quigley, N.R., P.E. Tesluk, E.A. Locke, and K.M. Bartol (2007) "A Multilevel Investigation of the Motivational Mechanisms Underlying Knowledge Sharing and Performance", Organization Science (18)1, pp. 71-88.

[16] Siemsen, E., S. Balasubramanian, and A.V. Roth (2007) "Incentives That Induce Task-Related Effort, Helping, and Knowledge Sharing in Workgroups", Management Science (53)10, pp. 1533-1550.

\section{Appendix A. Fact Table for Bordia et al. Article}

\begin{tabular}{|l|l|l|l|l|}
\hline FactID & CitationID & ConsistencyResult & CatPredictandVarName & OpPredictandVarName \\
\hline 1 & 1 & Consistent & Knowledge Sharing & InterpersonalKSInt \\
\hline 2 & 1 & Consistent & Knowledge Sharing & RepositoryKSInt \\
\hline 3 & 1 & Indeterminate & Knowledge Sharing & InterpersonalKSInt \\
\hline 4 & 1 & Consistent & Knowledge Sharing & RepositoryKSInt \\
\hline 5 & 1 & Indeterminate & Knowledge Sharing & InterpersonalKSInt \\
\hline 6 & 1 & Consistent & Knowledge Sharing & RepositoryKSInt \\
\hline
\end{tabular}


Fact Table Columns - continued

\begin{tabular}{|l|l|l|}
\hline \multicolumn{1}{|c|}{ OpPredictorVarName } & \multicolumn{1}{c|}{ PredictorVarTypeName } & \multicolumn{1}{|c|}{ SignificanceResult } \\
\hline Evaluation Apprehension & Human & Negative Significant \\
\hline Evaluation Apprehension & Human & Negative Significant \\
\hline Extrinsic Reward & Organizational & Not Significant \\
\hline Extrinsic Reward & Organizational & Positive Significant \\
\hline Evaluation Apprehension * Extrinsic Reward & Human-Organizational & Not Significant \\
\hline Evaluation Apprehension * Extrinsic Reward & Human-Organizational & Positive Significant \\
\hline
\end{tabular}

Fact Table Columns - continued

\begin{tabular}{|l|l|l|l|}
\hline ResMethName & SubTypeName & \multicolumn{1}{c|}{ TheoryName } & Count \\
\hline Survey & Workers & Social Exchange Theory & 1 \\
\hline Survey & Workers & Social Exchange Theory & 1 \\
\hline Survey & Workers & Social Exchange Theory & 1 \\
\hline Survey & Workers & Social Exchange Theory & 1 \\
\hline Survey & Workers & Social Exchange Theory & 1 \\
\hline Survey & Workers & Social Exchange Theory & 1 \\
\hline
\end{tabular}

\section{Appendix B. Applications of the Framework Dimensions}

\begin{tabular}{|c|c|}
\hline Dimension & Application \\
\hline $\begin{array}{l}\text { Consistent } \\
\text { with Theory }\end{array}$ & $\begin{array}{l}\text { Not Consistent and Indeterminate outcomes are a potential source of future research. Many times an independent variable } \\
\text { will be found to be consistent in some studies and not consistent in others. Further research may be required to verify that } \\
\text { the attributes that differ between the studies are the source of the conflicting findings. Indeterminate outcomes should also } \\
\text { be of great interest because research variables are carefully chosen and motivated by theory and when outcomes don't } \\
\text { align with predictions this represents a gap in our knowledge that should be bridged. }\end{array}$ \\
\hline Theory & $\begin{array}{l}\text { Including this dimension allows researchers to ask questions of their literature review data such as what theories have been } \\
\text { used in this domain, what variables have been explored associated with a particular theory, and what findings have resulted } \\
\text { from the use of this theory. }\end{array}$ \\
\hline Year & $\begin{array}{l}\text { This dimension allows researchers to analyze the corpus of literature based on time. Analysis using this dimension includes } \\
\text { patterns of outcome variables over time and the frequency of theory use. }\end{array}$ \\
\hline $\begin{array}{l}\text { Subject } \\
\text { Type }\end{array}$ & $\begin{array}{l}\text { This dimension allows for the comparison of research variable outcomes across different subject types. At times this may } \\
\text { be the source of conflicting findings among studies. Reliance on a specific subject type such as students may show a need } \\
\text { to do research in a business-specific domain where knowledge-sharing problems are particularly acute. }\end{array}$ \\
\hline $\begin{array}{l}\text { Independent } \\
\text { Variable }\end{array}$ & $\begin{array}{l}\text { This dimension can be used to identify what variables have been tested, suggest variables that have not been tested, and in } \\
\text { many cases identify variables that have been under-tested. In this review we found that in a large portion of the cases in } \\
\text { which a variable was tested once, mixed results were found. }\end{array}$ \\
\hline \begin{tabular}{l|} 
Independent \\
Variable \\
Significance
\end{tabular} & $\begin{array}{l}\text { Variables that are suggested to have an impact based on theory but regularly are identified as not significant are a key } \\
\text { source for future research. Also, conflicting findings suggest a need for further study. }\end{array}$ \\
\hline $\begin{array}{l}\text { Independent } \\
\text { Variable } \\
\text { Category }\end{array}$ & $\begin{array}{l}\text { Identifying relevant categories of variables that need to be controlled for can be critical to interpreting research results. In } \\
\text { this review, different results for the same variables were regularly observed when one category of variables was tested in } \\
\text { one study and multiple categories were tested in another. An example of an uncontrolled result would be testing variables } \\
\text { related to human behavior alone compared to human behavior along with organizational or technology variables. }\end{array}$ \\
\hline Citation & The citation dimension aids future researchers in locating the studies with interesting findings. \\
\hline $\begin{array}{l}\text { Research } \\
\text { Method }\end{array}$ & $\begin{array}{l}\text { Findings of previous studies can be weighed and contrasted in light of the research approach utilized. A finding from a } \\
\text { survey related to intended behaviors may conflict with findings based on actual behaviors. Future studies can be designed } \\
\text { to clarify the nature of such conflicts. }\end{array}$ \\
\hline $\begin{array}{l}\text { Dependent } \\
\text { Variable }\end{array}$ & $\begin{array}{l}\text { The classifications of dependent variables can be used to make cross-study comparisons. In this case, knowledge sharing } \\
\text { and knowledge hoarding were both key categories for dependent variables, but knowing that these were opposing ideas is } \\
\text { necessary when interpreting the positive or negative associations of the independent variables. }\end{array}$ \\
\hline \begin{tabular}{l|} 
Dependent \\
Variable \\
Subcategory
\end{tabular} & $\begin{array}{l}\text { The way that a study operationalizes a dependent variable such as knowledge sharing can have a clear impact on research } \\
\text { results. One example of this is that the same independent variables were tested on slightly different dependent variables } \\
\text { (repository-based knowledge sharing vs. face to face sharing) and different results were observed. Noting such conflicts } \\
\text { may indicate an opportunity for theory development to account for such differences. }\end{array}$ \\
\hline
\end{tabular}

